\title{
简议电网系统输电线路工程的施工技术及其安全管理
}

\author{
吴金文 1 郭士轶 2 柴仁勇
}

1 国网新余供电公司 2 国网吉安供电公司

DOI:10.32629/hwr.v3i12.2621

[摘要] 电网系统输电线路工程建设是保证电力安全可靠输送的关键, 因此为了保证电网系统输电线路工程电力的安全输送, 需要将其施工技 术及其安全管理进行严格控制, 从而保障电网系统的安全可靠运行。基于此, 本文简述了电网系统输电线路工程建设的主要内容, 对电网系统输 电线路工程建设的施工技术要点及其安全管理进行了论述分析。

[关键词]电网系统; 输电线路工程建设; 内容; 施工技术要点; 安全管理

\section{1 电网系统输电线路工程建设的主要内容}

电网系统输电线路工程建设的内容主要有输电线路的基础施工、输电 线路的杆塔和架线施工、输电线路的维护和检修施工三个部分组成。输电 线路的基础主要是指杆塔埋在地下的部位, 主要受外部环境的影响, 以确 保杆塔的稳定性而不会下沉, 倾斜和变形。输电线路的杆塔主要在输电线 路中用来起到支撑线路的作用。杆塔的结构主要从输电线入的受力, 杆塔 的外部结构和杆塔组建方式的三方面来考虑。输电线路的施工主要包括施 工准备, 连接放线导地线, 跟踪观测线路的弛度, 输电线路辅助部件的安装 以及进行紧线作业。输电线路的维护和修理主要涉及输电线路的专业维护 人员对线路进行例行检查和维护。如果发生特殊事故或故障, 请及时维修 管道, 以确保变速箱正常运行。

\section{2 电网系统输电线路工程建设的施工技术要点分析}

2. 1 基础施工技术要点

(1) 基坑施工主要技术要点。例如, 岩石基础的开挖需要根据不同的岩 石类型选择不同的方法。对于未风化或者风化较差的岩石, 通常将地基埋 在覆盖层内, 并选择钢钎打孔的方式。对于已风化或强风化的岩石基础, 基础的开挖应确保基础的完整性和稳定性。(2)复合式沉井地基施工的要 点: 复合式沉井地基通常用于地下水水位较高的软土地基以及易受“流砂” 现象的地基处。它主要由地上台阶基础和地下钢筋混凝土箱两部分组成, 它们组成一个统一的整体。在施工安装过程中, 普通地基的安装深度通常 约为 4 米, 下部沉井的直径约为 2.55 米, 深宽比约为 1.5 。（3) 坑基排水的主 要技术要点: 坑基排水有两种: 明渠排水和暗渠排水。明渠排水方法主要 使用机原从基础内预先设置的集水井中向外排出。这通常适用于铁沉箱法, 混凝土护筒法和沉井法。暗渠排水一般将滤水器和井管在基坑周围埋设, 并连接总管路, 以降低地下水位。(4) 回填塔杆基础坑技术要点: 回填土的 压实程度取决于杆塔基础的形式。例如, 对于现浇混凝土铁塔基础和拉线 基础, 原始土壤的压实度通常大于 $70 \%$, 而对于不拉线的塔基础, 初始土壤 压实度通常大于 $80 \%$ 。由于带拉线的基础由于承受很大的抵抗力, 通常使 用分层回填土填充方法。

2. 2 杆塔施工技术要点

电力工程建设的杆塔在输电线路中具有非常重要的作用, 其主要用来 支撑整个输电线路, 是输电线路中最重要的施工工序。杆塔的使用时间相 对较长, 为了保障杆塔具有较强的承载力, 这就要求杆塔必须具备较强的 刚度和硬度。在选择杆塔时, 在减少成本支出的同时, 还应该综合考虑杆塔 的形式和结构。杆塔的选用受地区的影响, 如果是在平原、丘陵等地区进 行施工建设, 通常选用钢筋混凝土杆或者应力混凝土杆, 如果在海拔较高 的山地进行线路施工, 通常选用铁塔。目前, 线路施工中经常用到杆塔组合, 分解组立和整体组立是比较常见的两种组合形式。由于钢筋混凝土杆的质
量较大, 通常在地面上将其组装完整后再进行整理组立。最后, 工作人员还 应该明确, 钢筋混凝土构件容易出现裂缝等问题, 张拉钢筋后, 再进行混凝 土浇筑。

2.3 光缆施工技术要点

电网系统输电线路工程施工还应该做好电缆防雷工作。首先, 在线路 施工之前, 施工人员应该首先对设计数据有透彻的了解, 以确保在施工中 考虑材料的质量和安全性。其次, 施工人员还应检查光缆, 并使用OTDR进行 特定测试。施工人员应与专业人员合作进行, 以确保光缆的质量和连续性。 第三, 在焊接光缆时, 施工人员还应该选择合适的焊接位置为了防止水气 进入光缆, 工作人员还应使用密封性能更好的接线盒来完成焊接操作。光 缆的熔合完成后, 施工人员必须在接线盒的位置开始收揽。主要目的是确 保接线盒中灯具的原始形态。

2. 4 架线施工技术要点

架线施工需要综合考虑架线样式和架线要求之间的关系, 结合架线施 工的实际状况选择合适的架线展放方式, 常见的展放方式有以下两种: 第 一, 拖地展放。工作人员应该明确拖地展放现盘位置不需要进行制动, 电线 可以直接在地上拖动前行, 相对而言比较简单, 但是, 电线在拖动的过程中 容易产生较大的摩擦力, 电线会因此受到严重的损坏。拖地展放由人工进 行施工作业, 劳动效率也相对较低。第二, 张力展放。这种方法通常运用在 较高电压的线路施工中, 这种方法可以增强地线之间的张力, 从而降低电 线的磨损程度。

\section{3 电网系统输电线路工程建设的安全管理}

电网系统输电线路工程建设的安全管理主要表现为:（1）完善健全安 全生产保障制度。根据《电工技术安全规定》和《健康安全管理体系》, 建立完整的安全保障体系。根据项目制定的总体安全目标, 将其逐层分解 并为每个施工团队实施。制定各级安全管理文件和安全保障机制。(2) 确 定施工的安全管理目标。在建设输电线路项目之前, 该施工单位必须根据 《中华人民共和国安全生产法》的有关法律法规和施工单位的总体控制目 标设定安全施工技术的安全目标。然后, 对总体目标进行逐层分配, 以便 各级部门甚至每位员工都有一个明确的安全目标, 该目标将用作每位员工 的考核指标。(3) 组织施工安全管理计划。在建设电网系统输电线路工程 之前, 需要组织工程部门的施工技术人员对施工单位提供的勘测设计文件 进行详细的检查和审查, 并充分了解有关信息。输电线路项目的信息, 包括 周围的气候, 地质, 地貌, 地基类型, 沿线地区的差异等。组织技术人员分析 所有可能的不安全因素, 并事先采取针对性的预防措施。二是根据工程的 总体施工周期和工程量, 设置施工安全管理岗位和管理人员, 控制安全工 具和材料的投入, 确保满足安全施工的所有要求。(4) 充分做好施工安全管 理技术。电网系统输电线路工程建设安全管理技术的建设, 要求严格执行 


\section{装表接电错误接线分析及防窃电管理措施}

施涁

国网福建龙海市供电有限公司

DOI:10.32629/hwr.v3i12.2573

[摘 要] 近年来, 电力消耗每年都在增加, 但是有时会发生盗窃, 为了确保不损害企业和用户的经济利益, 电力公司需要加强电表装表工作避免 发生窃电的现象。随着市场经济的发展, 社会生产活动日益增多, 人们生活和工作需要越来越多的电能, 极大地促进了电力公司的发展。

[关键词] 装表接电; 接线错误; 窃电管理

\section{前言}

在市场上, 电能是可以用作商品的能源, 用户使用电能时必须按照相 关的收费标准缴纳一定的费用, 这构成了供电企业的用户与产品之间的关 系。但是, 一些不法分子利用非法手段窃取电能以谋取自身利益, 这损害了 公用事业公司的经济利益, 对电力系统的稳定运行有一定影响。

\section{1 装表接电时接线错误的原因}

电表连接的质量直接影响电能计量的准确性, 因此有必要加强计量操 作的质量控制, 以免损害电源的经济效益和电力系统的可靠运行。但是, 在实际操作中, 有许多因素会影响测量精度, 由于电路复杂, 在安装过程中 工作人员会忽略, 很容易引起接线错误。计量操作完成后, 设备得不到定期 维护和保养从而导致测量数据出错, 在调整电源线相序后没有相应地调整 计量设备都可能会引起计量的不准确。

除上述影响因素外, 还有人为破坏因素。一些用户为了自己的利益修 改设备, 以达到窃取电能的目的。通常, 他们将设备的零线和火线反向连接, 而中性线断开, 带电线路与电能表直接连接, 因此可以正常供电, 因为电流 不会直接流过电能表的线圈。如果所使用的电能表是三相线路中的两相电 能表, 则如果将三个电压线混合在一起, 则电能表将无法正常工作, 并且计 量装置也将显示零。在使用三相四线电能表的情况下, 不良接触或中性线 的老化会导致不良接触, 并且电能表内的电流互感器可以与电能表内的电 流互感器断开, 如果连接不正确, 则一相连接错误将影响电能表的运行速 度, 因此来自测量设备的数据低于实际功耗。如果两个或三个互感器连接 不正确, 则电能表将反转。

\section{2 盗电造成的损害}

窃电行为是近年来电力公司最严重的问题之一, 这种行为对国家社会 的不良影响是不言而喻的。我们经常看到这样的消息: 由于电表的电击造 成个人用户起火, 这给用户造成了经济损失, 其中一些人失去了宝贵的生 命。发生这样的悲剧证明了窃电对人们生命和财产安全的威胁。窃电时, 用户并不十分了解具体的电路, 操作不当可能对他造成的损害, 同时盲目
地修改了电表也会在在电路中造成隐患。窃电的行为不仅不能保证自身的 生命和财产安全, 而且会影响邻居的生命和财产的安全。其次, 窃电行为会 导致电表停电或减少计量数量, 大大降低了用户的电费, 这意味着用户的 耗电量和电表显示存在较大的差距。他们中的大多数人都采用随机布线的 方式来达到窃电的目的, 这很容易损坏电源, 不仅容易发生大规模停电事 件, 而且还可能直接引起爆炸或火灾, 危及人们的生命财产安全。中国的供 电方式一般分为水电, 能源和风能, 这些能源是有限的, 特别是能源是不可 再生的资源, 对我们来说是宝贵的资产。通过窃电行为对电力资源的使用 是间接的能源浪费, 如果每个人都这样做, 非可再生资源的消耗将加速, 生 态系统将被破坏, 我们的将会流失宝贵的能源 ${ }^{[1]}$ 。

人们从电费中获得的收入是中国财政收入的重要来源, 因此, 为了窃 取国家财产并阻碍国家发展, 必须采取防止窃电行动管理, 以谋取国家或 企业的利益。各种盗窃对供电公司造成经济损失, 并影响生产和经营决策, 由于必须将一些资金用于防盗行为管理和技术部门发展, 企业的管理成本 增加。

\section{3 防窃电管理措施}

窃电的风险如此之大, 人们需要提出适当的防盗管理措施, 以限制窃 电行为。在进行窃电行为的管理时, 必须从多个方面进行改进, 首要的是提 高计量设备的质量, 确保计量设备的进度, 其次是提高技术人员的专业水 平, 另外还必须加强相关部门的监管 ${ }^{[2]}$ 。

3. 1 计量设备改进

苆电的方法不断更新, 因此老式的通用电表不再能阻止这种操作, 需 要对电表技术进行创新。在装入新的电表的过程中, 有必要严格检查用户 电路, 仔细检查自转换电路和安全隐患, 以确保接线表在安装过程中没有 接线错误。完成后, 相关检查人员必须重新测试电表, 并与用户记录并签署 相关法律协议。在基于用户的电源数据传输过程中执行良好的切换, 仔细 记录它们, 避免遗漏和其他问题, 并为分析将来的用户功耗变化提供基础。 实施印章系统管理, 确保印章数量上有相应的代码和工作人员记录, 以确
三级安全技术交付系统。在分部或分项目启动之前, 建设单位, 施工单位的 项目管理人员, 施工队伍的现场安全负责人和施工人员应向施工单位提供 层层安全技术。确保施工安全。并且有必要加强施工现场的安全检查。在 电网系统输电线路工程建设过程中, 有必要定期对各项工作进行安全检查, 重点调查违法违规行为, 发现问题, 立即按照工程部门的规定进行处理。相 关的生产安全文件。

\section{4 结束语}

综上所述, 随着城市化建设的不断推进, 使得国内基础设施建设不断 增多, 而电力工程建设是基础建设的重要内容, 其在人们日常生活中具有 重要作用, 其中输电线路施工及其安全管理对于电力工程的安全运行非常
重要, 因此必须加强对电网系统输电线路工程的施工技术及其安全管理进 行分析。

\section{[参考文献]}

[1]郭海燕.浅谈电力工程中高压输电线路施工技术与检修[J].建材与 装饰,2018,(23):228-229.

[2]郝慧洋. 电力工程输电线路施工技术与检修 [J]. 科技创新导 报,2019,16(20):25+27.

[3]李伟.输电线路运行安全影响因素分析及防治措施[J].电子世 界,2018,(03):189-190.

[4]无明洋.电力输电线路安全运行的探讨[J].数字通信世界,2017,(12):278. 